\title{
EL DERECHO HUMANO A LOS PATRIMONIOS CULTURALES EN CLAVE DECOLONIAL
}

RESUMEN: Pensar en el tratamiento, contenido y la exigibilidad de un "nuevo derecho" humano al(os) patrimonio(s) cultural(es) expresa la complejidad y dificultad de definir los derechos humanos, y las insuficiencias de hacerlo desde un registro exclusivamente normativo/jurídico positivo. Nuestro intento, entonces, no se reduce a concebir una fórmula orientada a la consagración del derecho humano al patrimonio cultural en una norma jurídica enmarcada en la promesa moderna de ciudadanía y democracia global; sino que pretende ir más allá, indagando los procesos socio-históricos que perfilan las articulaciones locales de las relaciones de diferentes colectivos en torno a lo patrimonial, y de los conflictos asociados a ellas, que en Argentina -desde donde escribimos como lugar geográfico pero también epistémico-, se vinculan a la persistencia de una matriz de colonialidad del poder, del saber y del ser.

Palavras clave: Derechos Humanos. Derechos Culturales. Patrimonio Cultural. Giro Decolonial.
ABSTRACT: Think of treatment, content and enforceability of a "new human right" to Cultural Heritage expresses the complexity and difficulty of defining human rights, and inadequacies from an exclusively legislative/positive legal perspective. Our intent , hen, is not confined to conceive consecration of the human right to cultural heritage in a legal rule framed in modern promise of citizenship and democracy global formula; but aims to go further, investigating the socio-historical processes that shape local joints relations of different groups around the estate, and conflicts associated with them, which in Argentina from where we write as geographical but also epistemic location-, they are linked to the persistence of a matrix of coloniality of power, knowledge and being.

Keywords: Human rights .Cultural rights. Cultural Heritage. Decolonial twist

\footnotetext{
${ }^{1}$ Profesora Adjunta, Investigadora y Coordinadora de la Comisión de Derechos Culturales del Observatorio Universitario de Derechos Humanos de la Facultad de Cs. Económicas y Jurídicas de la Universidad Nacional de La Pampa (Argentina).

${ }^{2}$ Profesor Titular Ordinario de Derecho Político en las Universidades Nacionales de La Plata y La Pampa. Profesor Adjunto de Introducción a la Sociología en la Universidad Nacional de La Pampa. Doctor en Derechos Humanos y Desarrollo (Universidad Pablo de Olavide. Sevilla. España), Máster en Teorías Críticas del Derecho y la Democracia en Iberoamérica. (Universidad Internacional de Andalucía. España. Entre sus más recientes publicaciones se encuentran los libros “El malestar en la cultura jurídica” (2011, EDULP,UNLP), “La Constitución Horizontal” (2013, EDULP, UNLP) y "Otros nomos: teoría del nuevo constitucionalismo latinoamericano" (UASLP, 2016).
} 


\section{INTRODUCCIÓN}

Entendemos derechos humanos son procesos culturales, históricos y sociales de apertura de espacios de lucha -institucionales, normativos, políticos- por las plurales formas de entender y practicar la dignidad humana (HERRERA FLORES, 2005). De donde su listado está siempre abierto a la reivindicación de nuevos derechos, de ahí su carácter instituyente, y no solamente instituido, y de ahí su carácter eminentemente crítico, en tanto los derechos expresan predicados normativos inconformistas acerca de las formas en que vivimos. Es decir, acerca de cómo nos relacionamos los seres humanos entre nosotros en los espacios culturales y biofísicos que co-habitamos. Acerca de cómo jerarquizamos y clasificamos las relaciones e identificaciones en base al sexo, la cultura, la clase, los fenotipos, la pertenencia a un grupo identitario, y reconocemos necesidades e imputamos satisfactores sociales en base a esas clasificaciones jerarquizadas.

Las subjetividades de derechos, se han ido concretizando y pluralizando en los procesos de lucha y reconocimiento, que nunca han sido formulaciones tecnocráticas 'desde arriba', sino verdaderas respuestas a desafíos y críticas sociales que, independientemente de cual sea el resultado histórico en términos normativos, son sintomáticas de cambios en las formas de percibirnos como sociedad y de relacionarnos como sujetos sociales.

Para esos procesos sociales la modernidad occidental, no sin claroscuros, ambigüedades, avances y retrocesos, ha generado el significante de la dignidad humana: derechos humanos como discursividad disponible para ser (re)enunciada desde nuevas necesidades, subjetividades y situaciones. Por eso el carácter tensionado entre lo instituido y normado y lo instituyente y normante del campo de los derechos humanos que nunca puede cerrarse - no hay un fin de la historia de los derechos humanos-. Derechos humanos exhiben una historicidad abierta y diversos usos posibles.

Joaquín Herrera Flores (2005, p. 122), desde su concepción de los derechos humanos como productos culturales, sostiene que éstos no son neutrales, sino que pueden desempeñar un rol que tienda a la regulación o a la emancipación. En el primer 
caso, contribuyen al mantenimiento del statu quo; en el segundo, a la transformación. En el mismo sentido, Boaventura de Sousa Santos (2009, p. 13) sostiene que los derechos humanos, en su complejidad, pueden desempeñar un rol hegemónico o contrahegemónico. Este último requiere para el autor una concepción multicultural de los derechos humanos

Las dimensiones del derecho en tanto orden normativo y de las políticas públicas son entonces mediaciones y herramientas no menores sino centrales en esos procesos complejos de derechos humanos, pero no los agotan ni estos pueden reducirse a aquellas. En todo caso hay que conocerlas, comprenderlas y sobre todo saber usarlas como herramientas de avance de los derechos en contextos problemáticos y conflictivos de gran complejidad social.

Resulta entonces fundamental una consideración del derecho humano a los patrimonios culturales que se sitúe decididamente en la mirada del pluralismo y de la interculturalidad, que critique el patrimonio cultural en singular, entendido desde la idea de nación monocultural, que identifique la matriz de colonialidad del poder, del saber y del ser que lo atraviesa y que dé cuenta de los derechos más específicos, de individuos y grupos en torno a los procesos de selección y gestión patrimonial.

\section{EL PATRIMONIO CULTURAL COMO PRODUCTO DE LA MODERNIDAD}

La conservación del patrimonio cultural nació en Europa, en el siglo XIX, cuando la antropología y la historia del arte se preocuparon por abordarla científicamente, y constituye un rasgo de la modernidad ${ }^{3}$ (GALI BOADELLA, 2001; HERNANDEZ i MARTI,

\footnotetext{
${ }^{3}$ 'Modernidad' es un término de difícil definición desde que ha suscitado debates e interpretaciones contradictorias. El significado más extendido la ubica como un fenómeno generado en occidente hace 500 años y luego extendido a otras sociedades y culturas, basado en ciertos principios organizativos: el capitalismo, la industrialización, la democracia liberal, el Estado-nación, el racionalismo, la familia burguesa. La modernidad se construye por oposición a lo tradicional (entendido como primitivo), desde un esquema de evolución progresiva que se autorrealiza, y se expresa en una serie de rupturas, que marcan una distancia histórica con el medioevo, y que contribuyen a explicar la dicotomía moderno/tradicional en distintos ámbitos. Así las categorías capitalista/pre-capitalista, pensamiento mágico/pensamiento científico, sagrado/secular, se constituyen en las claves de un trazado jerarquizado del espacio y del tiempo, donde Occidente es a la vez el pasado, en que se ubica el origen de la modernidad y el futuro, como horizonte al que todas las sociedades deberían aspirar. Estos procesos se expresan en distintos tiempos y en distintos lugares del mundo, por lo que también se ha hablado de 'modernidades' en plural (Szurmuk y Mckee, 1999). Desde América Latina, el grupo modernidad/colonialidad, propone una mirada crítica sobre el fenómeno, señalando una relación de co-constitución mutua entre 'modernidad' y 'colonialidad', que se asocia al surgimiento del nuevo patrón
} 
2008). Uno de los procedimientos más básicos de las políticas patrimoniales hegemónicas es la atribución de valores, fundamentalmente históricos, estéticos y de uso (VILADEVALL i GUASCH, 2003, p. 17). Esta concepción de lo patrimonial llevó a la postre a una idea de puesta en valor económico de los bienes culturales susceptibles de ser admirados por su historia o belleza y al nacimiento de un mercado que mueve cifras astronómicas a su alrededor.

Si bien la idea tradicional del patrimonio se desarrolla con fuerza en la Europa del siglo XIX, es un fenómeno cuya genealogía en la cultura occidental es antigua. Deriva de las primeras formas de apropiación, vinculadas al coleccionismo de objetos, y por ende, se la asocia a la idea de propiedad privada.

En la Antigüedad y durante la Edad Media, los bienes culturales se adquirían, en la mayoría de los casos, como botines de guerra. Por eso eran valorados sólo desde su contenido económico, derivado de la rareza de sus materiales. Se los desligaba entonces de las expresiones culturales de los pueblos vencidos o conquistados. Su disfrute era individual o privado y se relacionaba con la expoliación (LLULL PEÑALBA, 2005).

Como excepción a esta regla, se rescataban de la destrucción ciertos monumentos del mundo antiguo que tenían por objeto la rememoración de determinados héroes, personajes o hazañas (GALI BOADELLA, 2001, p. 35). De este modo, sólo se reconocía protección a aquellos bienes artísticos y/o escritos elaborados intencionadamente para recordar.

En el Renacimiento, los objetos comenzaron a ser valorados como testimonio de la historia, dando lugar a un nuevo concepto: el de monumento, y a nuevas técnicas de estudio, inventario, catalogación y mecenazgo. Etimológicamente, monumento procede del latín monere, que significa recordar, lo que pone de relieve no sólo la cualidad rememorativa sino sobre todo el valor documental de los bienes culturales y así se vincula al patrimonio con la capacidad de reflexión histórica. Ello llevará a sostener que fue en el

\footnotetext{
de poder mundial, capitalista y eurocentrado en el que se inscriben relaciones de dominación que configuran el universo específico de la modernidad. Para esta perspectiva, la colonialidad, que nace y se mundializa con la conquista de América "Se funda en la imposición de una clasificación racial/étnica de la población del mundo como piedra angular de dicho patrón de poder, y opera en cada uno de los planos, ámbitos y dimensiones, materiales y subjetivas, de la existencia cotidiana y a escala social" (QUIJANO, 2007: 93).
} 
Renacimiento cuando se originó la moderna conservación de monumentos y la instauración de normas jurídicas para su protección.

En la Edad Moderna, los bienes culturales no solamente sirvieron para rememorar y documentar el pasado, sino que además se constituyeron en modelos estéticos de la cultura clásica europea.

Fue luego de la Revolución Francesa cuando se produjo un cambio de concepción del patrimonio, que lo llevó desde el dominio privado al público, poniendo el acento en su valoración como símbolo de la identidad nacional, edificada sobre la idea de nación monocultural.

El interés por el tratamiento jurídico y político del patrimonio cultural se institucionaliza junto con el nacimiento del Estado-Nación, período en el que inscribirá el movimiento conservacionista moderno basado en un proceso de catalogación y selección resuelto -en última instancia- en un dictamen experto (BALLART, 1997, p. 53). Sin embargo, esa primera institucionalización no logró colocar al patrimonio en el ámbito del dominio público. Desde los orígenes, su regulación estará marcada por la colisión de este interés con la propiedad privada, derecho estelar y omnicomprensivo del estado liberal. Este es uno de los conflictos de intereses que están, a nuestro juicio, en los cimientos de la exclusión del patrimonio cultural en los principales instrumentos internacionales de protección de los derechos humanos.

La consideración del patrimonio nacional como bien público al que es preciso proteger por sus valores históricos, económicos y simbólicos, es decir como objeto de tutela estatal, eclosiona en los sistemas jurídicos de los Estados modernos de Europa y América, en el siglo XIX. Claro que, la regulación del patrimonio nacional tendrá un rol diferente en la configuración de las identidades nacionales en Europa que el que desempeñó en América. Es aquí ilustrativa la metáfora de la doble cara de la modernidad que plantea Mignolo (2001), porque en América, la idea de la identidad nacional, homogénea y genéricamente europea, narrada y reproducida mediante el patrimonio nacional, se sostiene sobre la cancelación violenta de la memoria y las culturas originarias (SEGATO, 2010; BRIONES, 2005). 
En este contexto surgirán las primeras normas jurídicas que establecerán criterios de protección, órganos de expertos, restricciones al dominio destinadas a la conservación e incluso la expropiación de bienes culturales. Este proceso se enriquecerá con la incorporación, a los museos europeos, de numerosos bienes culturales saqueados durante la expansión colonial ${ }^{4}$.

Paralelamente al desarrollo de la legislación interna sobre el patrimonio nacional, la regulación de los bienes culturales, y su valoración como bienes jurídicos protegidos ha sido materia de interés del Derecho Internacional, a instancia de los mismos Estados europeos. Este proceso de desarrollo internacional de normas jurídicas de protección, recomendaciones y políticas públicas en materia de patrimonio cultural, logrará expandir territorialmente y hacer hegemónicos los discursos y las políticas patrimoniales antes descriptos.

La Convención sobre la Protección del Patrimonio Mundial Cultural y Natural (1972), norma fundamental del sistema, establece un dispositivo basado en un sistema de listados de bienes culturales y naturales que son elegidos en base al criterio del 'valor universal excepcional $^{5}$, de otros catálogos de bienes propuestos por los estados parte en la Convención, pero no reconoce derechos de comunidades, grupos e individuos en relación a sus patrimonios culturales.

El concepto de patrimonio, reducido al patrimonio material, que sostiene el artículo primero de la Convención de 1972 y que, a partir de ella, se difunde a las normas de derecho interno de sus Estados signatarios, es el siguiente:

A los efectos de la presente Convención se considerará 'patrimonio cultural': - los monumentos: obras arquitectónicas, de escultura o de pintura monumentales, elementos o estructuras de carácter arqueológico, inscripciones, cavernas y grupos de elementos, que tengan un valor universal excepcional desde el punto de vista de la historia, del arte o de la ciencia, - los conjuntos: grupos de construcciones, aisladas o reunidas, cuya arquitectura, unidad e integración en el paisaje les dé un valor universal excepcional desde el punto de vista de la historia, del arte o de la ciencia, - los lugares: obras del hombre u obras conjuntas del hombre y la naturaleza así como las zonas, incluidos los lugares arqueológicos que

\footnotetext{
${ }^{4}$ En el mismo sentido, Benjamin (1995, p. 52) sostiene que el patrimonio cultural puede ser definido como un "documento de la barbarie"

${ }^{5}$ Una lectura crítica sobre la idea de patrimonio universal puede verse en Andrés M. Tello, "Notas sobre las políticas del patrimonio cultural" Cuadernos Interculturales, vol. 8, núm. 15, 2010, 115-131.
} 
tengan un valor universal excepcional desde el punto de vista histórico, estético, etnológico o antropológico ${ }^{6}$.

La plataforma de estos mecanismos consiste entonces en que los bienes culturales que resultarán incorporados a los listados, y que en consecuencia recibirán el financiamiento, la difusión y la asistencia técnica de la Organización, deben pasar por un doble tamiz, el de la 'identidad nacional' (al ingresar al listado de propuestas del Estado donde se encuentran) y el del 'valor universal excepcional' (para adquirir el carácter de patrimonio común de la humanidad).

Sin embargo, dicho 'valor universal excepcional', que aspira a constituirse en un criterio abstracto de selección (TELLO, 2010, p. 119), no es otra cosa que un localismo globalizado, entendido como "el proceso por el cual determinada condición o entidad local extiende su influencia a todo el globo y, al hacerlo, desenvuelve la capacidad de designar como local otra condición social o entidad rival" (SOUSA SANTOS, 2009, p. 12).

En efecto, los listados revelan un marcado carácter eurocentrado no sólo en cuanto a la prevalencia de bienes culturales europeos (TELLO, 2010; HERNANDEZ i MARTI, 2008), sino también respecto de la elaboración de criterios para alcanzar tal categoría, al sujetar la incorporación al Listado de Patrimonio Mundial Cultural y Natural al punto de vista de la historia, el arte o la ciencia, disciplinas cuya raigambre se inscribe en un patrón moderno/colonial del poder y del saber. Conforme a dicho patrón, en los considerandos de la Convención de 1972 se anuncia que es indispensable "un sistema eficaz de protección colectiva del patrimonio cultural y natural de valor excepcional organizada de una manera permanente, y según métodos científicos y modernos", lo que implica sustraer el proceso de selección a los pueblos soberanos que construyeron y dieron sentido a ese patrimonio.

En esta dirección, Tello (2010, p. 118) afirma que:

[el] listado actual del Patrimonio Común Mundial de la Humanidad (...), se basa en un supuesto criterio de 'valor universal excepcional' desde un punto de vista histórico, estético, científico y antropológico. Sin embargo, este listado no ha hecho sino afirmar una supuesta primacía cultural europea por sobre el resto de los continentes y culturas, a tal punto que sólo siete países europeos llegan a tener más nominaciones en esa lista que todo el continente americano.

\footnotetext{
${ }^{6}$ El destacado es nuestro.
} 
La Convención de 1972 subordina la protección del patrimonio cultural en el derecho internacional, a la inclusión de ciertos bienes culturales a los listados de patrimonio mundial de la UNESCO, a valores que se pretenden absolutos, pero no son otra cosa que mecanismos que favorecen la reproducción y legitimación de poder de sectores hegemónicos, cuyo capital cultural resulta jerarquizado frente a los bienes y prácticas de 'otros'.

\section{EL PATRIMONIO CULTURAL COMO DERECHO HUMANO}

El desarrollo de la protección internacional del patrimonio cultural, que hemos descripto a lo largo de este acápite, se produjo contemporáneamente al de los sistemas internacionales de protección de los derechos humanos, pese a lo cual, el tópico del patrimonio cultural, se mantuvo al margen de éstos, al no haber sido nombrado como derecho específico en ninguno de los instrumentos generales de protección del sistema universal que se lleva a cabo en el ámbito de la Organización de Naciones Unidas ni de los sistemas regionales ${ }^{7}$.Al mismo tiempo, los derechos culturales constituyen una categoría subestimada en el concierto hegemónico de los derechos humanos. ${ }^{8}$

En el año 2003, se aprueba la Convención para la Salvaguardia del Patrimonio Cultural Inmaterial, estrechamente vinculada al Convenio para la Promoción y Protección de la Diversidad de las Expresiones Culturales aprobado en 2005, que ha contribuido a ampliar la noción de patrimonio cultural en cuanto a su contenido y complejidad. En este sentido, se ha afirmado que:

Durante las dos últimas décadas, la noción de patrimonio ha cambiado sustancialmente y los sentidos de autenticidad, materialidad y monumentalidad, en los cuales estaba basada, han perdido fuerza. Ahora, se empieza a reconocer, desde las instituciones, que la cultura es dinámica, que el patrimonio debe hablar a través de los valores que la gente le otorga y no al revés. De esta manera, se empiezan a visibilizar, desde lo institucional, significados y expresiones culturales que no producen obras materiales monumentales o altamente estéticas, pero que son referentes simbólicos importantes para las sociedades que operan al margen

\footnotetext{
${ }^{7}$ Varios instrumentos reconocen el derecho de acceso a participar de la vida cultural: artículo 27 DUDH, artículo 27 PIDCP, artículo 15 PIDESC, artículo XIII DADH, artículo 14 del Protocolo de San Salvador anejo a la CADH. La Observación General №21 del Comité de Derecho Económicos Sociales y Culturales, aprobada en 2009, contiene algunas tibias referencias al patrimonio cultural al analizar el derecho previsto en el artículo 15 inc. a) del PIDESC.

${ }^{8}$ Un análisis sobre esta cuestión puede verse en Symonides (1998)
} 
de la lógica occidental y le dan mayor importancia a otras dimensiones sensoriales y de pensamiento (NUÑEZ, 2013, p. 6).

El contexto de surgimiento de las Convenciones de 2003 y 2005 se inscribe en el fenómeno de la globalización, que en ambos instrumentos se asocia a los riesgos de destrucción del patrimonio cultural inmaterial ${ }^{9}$.

En una relación de tensión dialéctica con la homogeneización cultural que arrastra la globalización, se produce otro fenómeno: la diferenciación, que se manifiesta la enunciación de identidades locales de las que el patrimonio cultural también es indudable testimonio. Estos procesos, se ven acompañados por surgimiento de organizaciones de la sociedad civil que se movilizan para reivindicar determinados bienes y prácticas culturales, desde su vinculación con las memorias e identidades colectivas, con los territorios, y con la mejora en la calidad de vida que se desprende de la búsqueda de una dignidad común con sentido histórico (HERNANDEZ i MARTI, 2008, p. 31). El ingreso de la sociedad civil como actora central de la cuestión patrimonial, estará en el núcleo de la vinculación que proponemos entre los patrimonios culturales y los derechos humanos.

\section{FUNCIÓN REGULADORA DEL PATRIMONIO CULTURAL Y SUS POLÍTICAS - EL CASO ARGENTINO}

En Argentina, la construcción del mito de la identidad nacional se desarrolló sobre un proceso de 'desetnicización' (GRIMSON, 2006), de ocultamiento de todo lo que pudiera considerarse no-blanco, que tuvo como antagonistas en primer lugar a los indígenas, luego a ciertos extranjeros (anarquistas, socialistas), más adelante a los 'cabecitas negras' del 'interior' y finalmente a los inmigrantes limítrofes.

La invisibilización de la diversidad cultural dio lugar a un "...mestizaje -crisol de razas, trípode das raças, cadinho- [que] se impuso entre nosotros como etnocidio, como cancelamiento de la memoria de lo no-blanco por vías de fuerza" (SEGATO, 2010: 26).

\footnotetext{
${ }^{9}$ Una discusión sobre la contribución de I.as políticas de la UNESCO a la globalización y homogeneización cultural puede verse en Gil-Manuel HERNANDEZ i MARTI, “Un zombi de la modernidad: el patrimonio cultural y sus límites”, La Torre del Virrey: revista de estudios culturales, № 5, 2008, 27-38.
} 
Esta práctica se consolida tachando el racismo del imaginario nacional (GARGALLO, 2006), de modo tal que:

la metáfora del crisol usada para construir una imagen homogénea de nación ha ido inscribiendo prácticas de discriminación generalizada respecto de cualquier peculiaridad idiosincrática y liberando en el proceso a la identificación nacional de un contenido étnico particular como centro articulador de identidad (una nación uniformemente blanca y civilizada en base a su europeitud genérica) (BRIONES, 2005, p. 21).

La matriz de colonialidad del poder, del saber y del ser y la idea moderna de nación implantada en nuestra región, sobre cuya réplica se construyeron inicialmente los estados provinciales, fueron determinantes en la idea de patrimonio cultural de la nación argentina como bien a tutelar. Sus formas elegantes y públicas de expresarse fueron la alta cultura de origen invariablemente europeo y la ciencia positivista -fuertemente imbricada en el darwinismo social- como expresiones de la civilización. Su otra cara fue el engranaje de violencia social -que articula sus manifestaciones estructurales, simbólicas y directas-.

En este sentido, es importante resaltar que las políticas públicas en materia de patrimonio cultural se encuentran atravesadas por intensas luchas por el dominio de los sentidos de identidad y pertenencia, donde los sectores hegemónicos que controlan los mecanismos de selección del patrimonio, resultan permanentemente interpelados por otros grupos, que cuestionan el modo en las identidades son representadas en el discurso patrimonial. Como sostiene TELLO $(2007$, p. 3)

[...] el trabajo hegemónico del patrimonio cultural y sus políticas, consiste en una disposición legitimadora de discursos y prácticas organizadas en torno a una 'narratividad específica', que convierte determinados productos culturales en memoria del pueblo o memoria nacional. Es en este montaje ficcional y hegemónico donde se juega parte importante del antagonismo social y cultural entre los grupos dominantes y los sectores subalternos.

Uno de los órganos nacionales que diseñaron la protección del patrimonio cultural en Argentina, fue la Comisión Nacional de Monumentos, Museos y Lugares Históricos, creada por ley 12.665 de 1940 . Como consecuencia de sus políticas y criterios de segregación/incorporación, el patrimonio cultural prehispánico se vio sub-representado en su diversidad y en su número, frente a la impactante cantidad de los sitios históricos vinculados al período patrio y colonial (ENDERE; ROLANDI, 2007, p. 36). 
La consideración de monumentos, restos y ruinas como objeto de clasificación, examen, y catalogación, fue la forma del tratamiento con la barbarie vencida e incluida en 'colecciones' museísticas -incluyendo restos biológicos humanos de pueblos originarios vivientes-, conjuntos arquitectónicos y espacios rituales de culturas existentes, intervenidos y catalogados como 'ruinas' de interés turístico e histórico educativo dentro de su funcionalidad a la construcción del patrimonio cultural de la nación. Como antecedente inmediato y fresco, de esa construcción inicial del patrimonio cultural y de la idea de nación concomitante, el trasfondo del genocidio social y cultural, denominado "Conquista del Desierto" 10, gigantesca operación apropiadora, reductiva y homogeneizadora que marca la institución sesgada del estado nacional, así como de las instituciones científico culturales en su seno, incluso las universidades nacionales formadas en ese período.

Un ejemplo que llama la atención respecto de lo que se juega en términos de autocomprensión en la construcción social del patrimonio cultural y sus diversos procesos y objetos culturales componentes, es la que conecta la historia de los restos humanos que fueron restituidos por la Universidad Nacional de La Plata (UNLP) a distintas comunidades originarias a partir de las últimas dos décadas del siglo pasado, con la idea de nación subyacente y con la concepción misma acerca de qué es, cómo se preserva y promueve el patrimonio cultural. El Museo de Ciencias Naturales de la UNLP, institución que custodia diez mil restos humanos pertenecientes mayoritariamente a pueblos originarios vivientes en el actual territorio nacional, y de otras naciones de la región, por sendas leyes del Congreso de la Nación, restituyó los restos del Lonko Inacayal a la comunidad mapuchetehuelche de Tecka, en la Provincia de Chubut. Posteriormente hizo lo propio con los del Lonko Panquitruz Guor, más conocido por su nombre colonial y cristiano como Mariano

\footnotetext{
${ }^{10}$ Así se denominó a la brutal campaña militar desarrollada entre 1878 y 1885 . La metáfora del 'desierto' utilizada para denominar a la campaña militar de ocupación del espacio, pese a que los territorios se encontraban densamente poblados, fue uno de los pilares de los discursos hegemónicos respecto de la identidad nacional, que se centró en la negación de toda referencia a la población indígena y la afirmación, en su lugar, del legado europeo o norteamericano (MORONI, 2005, p. 2). De este modo, se construyeron relatos identitarios al interior de los dispositivos de poder y de saber que pueden inscribirse en la lógica modernidad/colonialidad. El 'Desierto' se constituirá en la tabula rasa sobre la que se escribirá la identidad nacional, desarrollando un mecanismo de olvido activo, que exonera de toda responsabilidad sobre el genocidio.
} 
Rosas, a la comunidad ranquel de Leuvucó, en Provincia de La Pampa (BEGUELIN; GOMEZ, 2011).

No obstante, los debates previos en el Consejo Académico de la Facultad de Ciencias Naturales y en el Consejo Superior de la UNLP acerca de la responsabilidad de la institución en la preservación del patrimonio, dilataron la respuesta a las demandas que estaban planteadas inicialmente desde la década de 1970 y obligaron a la sanción de sendas leyes nacionales (23940/1994 y 25.276/2000) para solucionar un problema que la propia institución no pudo zanjar desde sus órganos de autogobierno.

En el primer caso, Inacayal, junto al Lonko Follel, y sus familiares más cercanos, después de ser apropiadas sus tierras por la guerra de conquista denominada por la historia oficial "Campaña del Desierto" y una vez rendidos, fueron engañados y deportados a Buenos Aires. Después de permanecer prisioneros en El Tigre, donde funcionaba uno de los centros de detención de los miembros de pueblos originarios -el otro funcionaba en la Isla Martín García- en condiciones absolutamente inhumanas y ejemplificadoras del 'estado de excepción' definido en el sentido filosófico de Giorgio Agamben y no en el jurídico constitucional -en tanto este supone limitaciones y controles sobre el poder del estado para disponer de la humanidad de sus 'enemigos'-, fueron llevados por el Perito Francisco P. Moreno al Museo de La Plata, que dirigía, y sometidos allí a servidumbre y exhibición como una 'colección humana viviente', disponible para fines educativos y 'objeto de estudio científico'. Follel pudo dejar el humillante confinamiento tras declararse 'argentino' e incluso recibir unas 'tierras fiscales' en la Patagonia, a la que retornó. Al Lonko Inacayal, en cambio, le tocó ver la muerte de sus familiares y la exhibición de sus huesos en un corto lapso de tiempo y corrió la misma suerte después de su muerte, producida en circunstancias dudosas, en el mismo lugar de su confinamiento, es decir, el museo plantense, en 1888. Sus huesos, cuero cabelludo y cerebro conservado en formol pasaron a integrar el patrimonio antropológico de la institución y por su intermedio de la Nación. En el caso de Panquitruz, los restos del líder ranquel fueron profanados del cementerio indígena por el militar Eduardo Racedo, en ocasión de la mencionada "conquista del desierto" y fueron a dar a la colección de Estanislao Zevallos, quien los donó al museo de La Plata. 
Resulta destacable que en el catálogo de antropología editado a principios del siglo XX (LEHMAN-NISCHE, 1910), figura número, origen y causas de la muerte de los sujetos a los que los restos pertenecen -principalmente óseos, y entre estos mayormente cráneos, aunque incluye también cerebros, cueros cabelludos, huesos y hasta cadáveres disecados-, existe una colección de los 'recientemente vencidos', otros murieron en su encuentro con las propias expediciones del museo a la Patagonia en circunstancias que deberían ser históricamente esclarecidas (BADENES, 2006):

Esqueleto 1769, "Petizo", toba, Resistencia (Chaco), fusilado en 1886 por orden del coronel Obligado, Colección Spegazzini.

Esqueleto 1786, "Michel", indio araucano (masculino), CorpenAiken (territorio de Santa Cruz), muerto en 1888 por expedición del Museo.

Esqueleto 1837, "Sam Slick", asesinado en Rawson, Chubut. Desenterrado por el doctor F. P. Moreno, viaje 1876-1877.

Las técnicas de la ciencia positivista darwinista descartaban, a la hora de verificar empíricamente la idea de evolución desde los estadios de salvajismo y barbarie a la civilización, junto a la importancia del grupo racial en la selección natural y la lucha por la vida, las técnicas más sofisticadas que, en (otros) contextos coloniales, empezaba a usar la antropología funcionalista británica, como la observación o la entrevista etnográfica, para persistir en el naturalismo y biologicismo ${ }^{11}$ de colecciones fotográficas realizadas en condiciones de desnudez de mujeres, niñas, niños, ancianos y hombres, medición antropométrica, descripciones anatómicas y fenotípicas, para después comparar con las características de la raza blanca, arquetípicamente en sus exponentes considerados entonces más 'puros'.

Estos estudios 'científicos'sobre restos humanos inertes y 'vivientes', tomados indistintamente como 'objeto', e integrantes del patrimonio científico de la institución y cultural de la nación, fungían como comprobación empírica acerca de la 'evolución' y 'progreso' de la República Argentina, a partir del mejoramiento, inevitable en la selección natural y la lucha por la vida, de su 'tipo humano'. Esta impronta permanece y se acentúa

\footnotetext{
${ }^{11}$ Todavía hoy la carrera de Antropología se estudia en la Facultad de Cs. Naturales y Museo en la UNLP. Aunque por supuesto, con una orientación de los estudios hacia lo cultural y social diversa de sus orígenes institucionales. No obstante, en el Museo de Ciencias Naturales siguen ocupando un lugar destacado, ligado a la historia de la institución, con una sala propia en exhibición, los muebles y utensilios de su primer director Francisco P. Moreno. La imagen humanista del mismo, sostenida por una fundación que lleva su nombre ligada desde hace tiempo a la institución, está puesta en entredicho y demandada su "desmonumentalización".
} 
en la transición del museo y su institución sede desde el carácter de universidad provincial a su carácter nacional, por ejemplo, en el propio discurso público de su fundador en la nueva etapa de universidad nacional, Joaquín V. Gonzalez ${ }^{12}$.

Este fenómeno, que con matices se ha dado en otros lugares de Latino América ha comenzado a transformarse a partir de la década del '90, cuando la diversidad étnicocultural aparece en la agenda política y jurídica de los estados latinoamericanos, en particular de la región andina. En ese escenario, la idea de identidad y junto a ella la de patrimonio cultural, ganaron centralidad en la agenda de estos países ${ }^{13}$.

De este modo, será solamente en las últimas décadas del siglo pasado y a partir del cambio que supuso la ratificación del convenio 169 OIT y la reforma de la constitución nacional en 1994 con su incorporación, de pésima técnica constitucional, de los derechos de los pueblos originarios como facultades legislativas del Congreso de la Nación en el art. 75 inc. $17 \mathrm{CN}$, cuando comenzará el proceso de revisión de las colecciones de restos humanos en los museos, la puesta en práctica de la restitución de los mismos a sus comunidades, como deber inherente a las instituciones estatales correlativa de los derechos de los pueblos preexistentes a los estados nacionales y provinciales, que implican una revisión crítica de la idea de patrimonio cultural, y del imaginario de la nación moderna/colonial que integra ${ }^{14}$.

\footnotetext{
12 “Eliminadas por diversas causas del tipo común nacional, los componentes degenerativos o inadaptables como el indio o el negro, quedamos solo los que llamamos mestizos por la mezcla del indio y el blanco. Pero a la vez, la evolución de un siglo, obrando sobre una proporción mínima de estos elementos, los elimina sin dificultad, y deja como ley de composición el tipo étnico nacional la de la raza europea, pura por su origen y pura por la selección operada en nuestro suelo sobre la sangre criolla, que es también europea. La enorme ventaja económica de esta evolución, no necesita acaso inventario o prueba: suprimidos los elementos de degeneración o corrupción, que significan debilidad, agotamiento, extinción y en otro orden ineptitud y falta de resistencia para el trabajo creador y reproductivo, quedaba, pues, un producto selecto de sangre blanca pura o depurada, cuyo coeficiente o "ratio" de potencia mental, de labor, de energía y voluntad, y cuya asimilación a las más altas formas de cultura se hallan demostradas por los resultados históricos de las más grandes nacionalidades contemporáneas"(1979, p.178-179) .

${ }^{13}$ El derecho humano a los patrimonios culturales integra las las nuevas constituciones del Estado Plurinacional de Bolivia (2009) y de la República de Ecuador (2008). Estos derechos culturales deben ser puestos en la sistemática de sus textos constitucionales como producto de procesos sociales y políticos que al operar una redistribución de poder social hacia los grupos históricamente subalternizados dentro de la matriz estatal moderna/colonial, fueron concomitantes con un cambio profundo en la autocomprensión de la nación que paso a valorizar su pluralismo cultural y a redefinir su historia e identidad.

${ }^{14}$ El reconocimiento de los derechos colectivos en el capítulo de los “Nuevos Derechos y Garantías" de la Constitución Nacional reformada en 1994, fue acompañado de la incorporación con jerarquía constitucional de 11 instrumentos internacionales de protección de los derechos humanos. Un análisis sobre los derechos culturales contenidos en los
} 
Es desde la herida colonial que, en casos como estos, el derecho humano a los patrimonios culturales emerge como una petición de principios hacia la reapropiación social, participativa y plural de las funcionescumple la construcción de los patrimonios culturales. Así entendido, el derecho a los patrimonios culturales es fundamental porque supone y requiere un imaginario de la nación plural social y culturalmente, que entreteje las narrativas de los sujetos sociales (de) (re) construyendo la memoria histórica, redefiniendo el 'nosotros' a partir de las alteridades subalternizadas e históricamente negadas y los 'legados' en forma plural para articular la dimensión de riqueza cultural y solidaridad intergeneracional.

\section{HACIA UNA RESIGNIFICACIÓN DEL PATRIMONIO CULTURAL}

Situar el patrimonio cultural en el campo de los derechos humanos, concebidos como procesos socio-históricos (GALLARDO, 2008) y culturales (HERRERA FLORES, 2005), implica a la vez reconocer que el sitio social en que se fundamenta este y los otros derechos humanos es la sociedad civil emergente, o lo que es lo mismo, sus movimientos sociales contestatarios (GALLARDO, 2008, p. 27) que pugnan por institucionalizar jurídicamente sus reclamos, cuestionando las lógicas del orden social existente y las identificaciones que ellas procuran.

Este proceso de innovación del derecho, atravesado por arduas luchas sociales y tensiones políticas, se dinamiza al reconocer la importancia de la participación política, de manera tal que los derechos vigentes no operen como bastión de resistencia a la aparición de nuevos derechos, sino que formen parte de un corpus, cuyo contenido y ejercicio puedan ser continuamente revisados (DUSSEL, 2010, p. 235).

Una resignificación y reapropiación del(os) patrimonio(s) cultural(es) a partir de su concepción como derecho humano requiere conectarlo con las comunidades que pugnan por reproducir y visibilizar su herencia cultural desde referentes identitarios que les son propios (NUÑEZ, 2013, p. 8) y crear los cauces para conferir garantías no sólo jurídicas, sino 
también sociales y políticas, para la apertura y consolidación de esos espacios de lucha por la dignidad.

\section{TRES DIMENSIONES DEL DERECHO HUMANO A LOS PATRIMONIOS CULTURALES}

El debate sobre los derechos culturales a partir de la reivindicación de la diversidad cultural, y el creciente número de ratificaciones que han logrado la Convención de 2005, lograron Ilamar la atención del Consejo de Derechos Humanos de las Naciones Unidas, que mediante Resolución 10/23, y en base a los resultados de consultas previas con organizaciones gubernamentales y no gubernamentales, decidió establecer en el año 2009 y por un período de tres años luego prorrogado, un nuevo procedimiento especial titulado "Experto independiente en la esfera de los derechos culturales"

La pakistaní FaridaShaheed inició sus funciones como Experta Independiente en la esfera de los derechos culturales en 2009, y desde 2015 ha sido reemplazada por Karima Bennoune como Relatora Especial en el mismo tema, de acuerdo con la resolución 19/6 del Consejo de Derechos Humanos de 2012.

Para el cumplimiento de su labor, las rapporteurs escogieron diversos enfoques sobre los derechos culturales que dieron origen a una serie de informes temáticos ${ }^{15}$.En el año 2011, el informe temático se centró en investigar la medida en que el derecho de acceso al patrimonio cultural y su disfrute forma parte de las normas internacionales de derechos humanos. Para ello, además del análisis de la normativa internacional, estatal y local respecto al patrimonio, se realizó un cuestionario del que participaron estados, organizaciones no gubernamentales y expertos, que, aunque no numerosos, fueron representativos de las múltiples miradas sobre la cuestión.

Consideramos al patrimonio cultural, como una construcción social, a partir de un proceso de selección simbólica, emocional e intelectual de bienes y prácticas culturales, que son continuamente resignificados, reapropiados y valorizados como referentes de identidad y de pasado de una comunidad, con la intención de ser transmitidos. La

\footnotetext{
${ }^{15}$ Sobre desafíos para una puesta en marcha de los derechos culturales (2010), el derecho a gozar de los beneficios del progreso científico y sus aplicaciones (2012), derechos culturales de las mujeres (2012), derecho a la libertad artística (2013), derecho a la memoria (2013-2014), el impacto de la publicidad y el marketing sobre el goce de los derechos culturales (2014) y los derechos intelectuales (2015).
} 
posibilidad de participar de esa construcción social y de los mecanismos de disputa y de consenso que dan lugar al proceso de selección significativa que convierte en patrimonio a ciertos bienes y prácticas culturales constituye entonces una manifestación de pertenencia, una identificación de un individuo con una comunidad, y en modo más amplio con una sociedad dada.

Ello significa que el acceso a esa posibilidad, que en definitiva se traduce en el acceso a bienes y prácticas culturales, se vincula a la dignidad humana, en tanto supone la aptitud de que los diversos grupos, sus visiones de mundo, sus identidades y sus memorias se encuentren representadas en el discurso patrimonial, lo que a la vez implica conectar a la cultura con su fuente de producción en un determinado territorio. Se trata entonces de una cuestión de derechos humanos.

Estos primeros pasos en la delimitación del contenido del derecho a los patrimonios culturales nos permiten destacar tres dimensiones que contribuyen a su consideración como derecho humano. La dimensión personal (individual y colectiva), la dimensión temporal y la dimensión territorial.

\section{a) Dimensión personal (individual y colectiva)}

Como afirma Cançado Trindade (1994, p. 63), todos los derechos humanos tienen una dimensión individual y una colectiva, en tanto son ejercidos en el contexto social. Sin embargo, ciertos derechos se relacionan más íntimamente con la vida en comunidad, lo que ha llevado a los juristas a hablar de una nueva categoría de derechos, no comprendida en los instrumentos generales de derechos humanos, a la que la doctrina mayoritaria ha llamado 'nuevos derechos humanos' o 'derechos de solidaridad' y que preferimos llamar derechos sobre bienes públicos relacionales ${ }^{16}$. Esta categoría de derechos reúne las siguientes características: a) su titularidad es amplia, derivada de su carácter colectivo y de interés público, que coexiste con una posible dimensión personal, referida a derechos individuales en sentido estricto; b) son derechos conglobantes, que actúan como condición de otros derechos más específicos y dependen de la generación de bienes públicos

\footnotetext{
${ }^{16}$ Denominación acuñada por Alejandro Médici (2013).
} 
relacionales, originando como contrapartida deberes públicos y privados; c) los bienes públicos relacionales, son condición y modulan el contenido de estos derechos que, en consecuencia, resultan indisponibles para el Estado, el mercado e incluso para sus propios titulares; d) son transgeneracionales, trascienden el tiempo de su producción y su conservación requiere solidaridad entre las generaciones presentes y las futuras; e) requieren garantías pluridimensionales, es decir, no solamente jurídicas, sino también políticas y sociales; f) finalmente, estos derechos para desarrollarse en plenitud, necesitan de "regulaciones públicas democráticas que, según los casos, eliminen, minimicen y vinculen jurídicamente a los poderes fácticos innominados privados, estatales o paraestatales que apropian o impiden la generación de los bienes públicos relacionales condición y contenido de esos mismos derechos" (MEDICI, 2013, p. 44).

Todas estas características ponen de resalto la interdependencia entre el derecho a los patrimonios culturales en su dimensión colectiva, y la participación democrática en sus diversos grados de cooperación e interacción ciudadana, a saber: a) la participación como derecho de acceso a la información, b) la participación como consulta, c) la participación como co-decisión y d) la participación como co-gestión ( $\mathrm{MEDICl,} \mathrm{2011,} \mathrm{p.} \mathrm{234).}$

\section{b) Dimensión temporal}

Pensar el patrimonio bajo el prisma de los derechos humanos es especialmente importante en Latinoamérica cuyas sociedades han atravesado procesos de violaciones masivas de derechos humanos, primero en relación con los pueblos originarios, luego, durante las dictaduras cívico-militares de la segunda mitad del siglo XX.

Es importante abordar cómo los procesos conmemorativos se traducen al campo patrimonial, mediante representaciones materiales o rituales alusivos que se expresan en el espacio público, y la responsabilidad de los diferentes actores (estatales y no estatales) en su producción.

En nuestro continente, la cuestión de la preservación de la memoria histórica ha influido en los procesos judiciales de reparación por las violaciones masivas de los derechos humanos, a partir de la tendencia marcada por la Corte Interamericana de Derechos Humanos, que desde sus primeras sentencias se ha preocupado por la 
producción de medidas de reparación que actúen en el plano simbólico y de la memoria, construyendo una verdadera doctrina jurisprudencial en la materia ${ }^{17}$.

De esta manera, es importante que el derecho a los patrimonios culturales fomente una cultura democrática a partir del debate sobre la representación del pasado, sobre las plurales y diversas identidades que configuran "la nación", así como los objetivos que persiguieron los discursos homogeneizantes, para asumir un desafío en el presente y hacia el futuro frente a la violencia y exclusión.

\section{c) Dimensión territorial}

Las relaciones entre patrimonio cultural y territorio pueden ser equívocas en términos de derechos humanos desde múltiples aspectos. Uno de ellos es la desconexión entre los bienes culturales y su territorio como consecuencia de la gestión patrimonial.

Esta situación resulta especialmente problemática para los pueblos que sufrieron el colonialismo, pero que también se identifica al interior de los Estados y ha originado reclamos y llamamientos a la repatriación de patrimonio cultural ${ }^{18}$.

\section{TRES RETOS PARA UNA CONSTRUCCIÓN DESCOLONIZADORA DEL DERECHO HUMANO A LOS PATRIMONIOS CULTURALES}

De estos tres aspectos, surgen entonces tres retos para avanzar hacia una consolidación del derecho humano a los patrimonios culturales en clave decolonial.

\footnotetext{
${ }^{17}$ Ver entre otros:19 Comerciantes v. Colombia, 2004 Corte I.D.H. (ser. C) No. 109, ๆ 273, ordenando un monumento con sus nombres en un lugar elegido por el E y los familiares de las víctimas; HuilcaTecse v. Perú, 2005 Corte I.D.H. (ser. C) No. 121, ๆ 115, requiriendo al E peruano erigir un busto en memoria de la víctima en un lugar público de la ciudad de Lima); La Comunidad Moiwana v. Suriname, 2005 Corte I.D.H. (ser. C) No. 124, ๆ 218, dirigiendo la construcción de un monumento cuyo diseño y ubicación fueran designados en consulta con los representantes de las víctimas; Gelman v. Uruguay, 2010 Corte I.D.H. (ser. C) No. 221, ๆ 267, ordenando colocar en un espacio del edificio del Sistema de Información de Defensa (SID) con acceso al público, en el plazo de un año, una placa con la inscripción del nombre de las víctimas y de todas las personas que estuvieron detenidas ilegalmente en dicho lugar.

${ }^{18}$ Existen múltiples ejemplos de repatriación de patrimonio en el plano internacional, algunos como resultado de negociaciones bilaterales, como la repatriación a Perú de piezas arqueológicas de Machu Picchu, que estuvieron durante cien años en poder de la Universidad de Yale, otros, bajo los auspicios del Comité Intergubernamental para la Promoción del Retorno de Bienes Culturales hacia sus Países de Origen que funciona en el ámbito de la UNESCO. En el plano normativo se puede mencionar el Artículo 12 de la Declaración de Naciones Unidas sobre los derechos de los pueblos indígenas, aprobada por la Asamblea General en su 107ạ sesión plenaria, el 13 de septiembre de 2007, establece la obligación de los Estados de "facilitar el acceso y/o la repatriación de objetos de culto y de restos humanos que posean mediante mecanismos justos, transparentes y eficaces establecidos conjuntamente con los pueblos indígenas interesados".
} 


\section{a) Recuperar la dimensión colectiva del derecho a los patrimonios culturales mediante una gestión democrática del patrimonio cultural}

El primer reto propone la recuperación de la dimensión colectiva del derecho a los patrimonios culturales a la luz del principio que pregona su gestión democrática. Ello supone la incorporación de mecanismos de participación democrática en el proceso de selección patrimonial.

En particular se proponen dos: las audiencias públicas y el consentimiento previo, libre e informado.

El procedimiento de audiencias públicas tiene raigambre constitucional en el principio de debido proceso sustantivo ${ }^{19}$, receptado en el art. 18 de la Constitución Nacional Argentina y en los principales instrumentos internacionales de protección de los derechos humanos. Si bien en su concepción original, esta garantía se reconocía sólo en su faz individual, es decir, como el deber del órgano jurisdiccional de oír a la persona involucrada antes de tomar la decisión que pudiera afectarlo ${ }^{20}$, hoy es pacíficamente aceptada por la doctrina su extensión a la dimensión colectiva, en aquellos casos en que no sólo la decisión judicial, sino también la decisión legislativa o administrativa involucre cuestiones de gran impacto social, económico, ambiental o cultural para la comunidad, con arraigo en la interpretación armónica de los artículos 18, 41, 42 y 43 de la Constitución Nacional.

La Acordada 30/07, de la Corte Suprema de Justicia de la Nación, estableció el régimen para las audiencias públicas y su aplicación a algunos casos de su competencia,

\footnotetext{
${ }^{19}$ El debido proceso es una garantía constitucional que protege a los individuos frente a la arbitrariedad del Estado. En su faz adjetiva, refiere a la necesidad de que los procedimientos judiciales se realicen de acuerdo a la ley, En su faz sustantiva, refiere a la regla de razonabilidad, que exige la concordancia de las normas de cualquier grado, y los actos públicos y privados con la Constitución Nacional.

${ }^{20}$ Este principio implica también el acceso al expediente y su pleno conocimiento, el derecho a la defensa, la prueba, a alegar y a que la decisión sea revisada por otro órgano.
} 
siendo las más notables por su difusión pública, las celebradas en los casos "Verbitsky" ${ }^{21}$, "Riachuelo"22 y "Ley de Medios"23.

Nos interesa señalar la filiación constitucional e internacional del derecho de la comunidad a ser oída en audiencia pública, ya que ello permite su aplicación aún en aquellos casos en los que la ley específica que regula la materia no la prevé, como sucede con el patrimonio cultural.

Es necesario recordar también que la participación política está reconocida como derecho humano en los principales instrumentos internacionales genéricos de protección, y que no se limita a los derechos electorales: Pacto de San José de Costa Rica, art. 23.1; Declaración Universal de Derechos Humanos, art. 21.1; Pacto Internacional de Derechos Civiles y Políticos, art. 25; Declaración Americana de los Derechos y Deberes del Hombre, arts. XIX y XX. En consecuencia, el estado se encuentra obligado internacionalmente a adoptar las medidas necesarias para su concreción.

Los principios que informan la audiencia pública son el debido proceso, publicidad, oralidad, informalismo, contradicción, participación, instrucción e impulso de oficio, economía procesal y gratuidad.

De este modo, como lo afirma Medici (2011, p. 222), la audiencia pública constituye uno de los mecanismos de innovación institucional, que desde el reconocimiento del (des)acuerdo abre la democracia a los requerimientos de un consenso exigente, que debe ser continuamente renovado, verificado y nunca presupuesto.

la forma de verificar y renovar el consenso exigente que el trabajo continuo de la democracia supone, consiste en activar los mecanismos de la democracia semidirecta, innovar institucionalmente en los mecanismos de la participacióndecisión, que tiene como supuesto el acceso a y la transparencia de la información pública y los mecanismos consultivos, tales como las audiencias públicas con la participación de las redes y el asociacionismo de la sociedad civil (MEDICl, 2011, p. 225).

\footnotetext{
${ }^{21}$ CSJN, "Verbitsky H. s/ Hábeas Corpus".

${ }^{22}$ CSJN, "'MENDOZA Beatriz Silvia y Otros C/ ESTADO NACIONAL y Otros S/ Daños y Perjuicios (daños derivados de la contaminación ambiental del Río Matanza - Riachuelo)".

${ }^{23}$ CSJN, “Grupo Clarín S.A. y otros c/ Poder Ejecutivo Nacional y otros s/ Acción Meramente Declarativa”
} 
El segundo mecanismo, cuya incorporación se propone, es el consentimiento previo, libre e informado. Originado en el derecho de consulta previa, de aplicación de los pueblos indígenas a partir de su incorporación en el artículo 6 del Convenio 169 de la Organización Internacional del Trabajo, resultó profundizado por la Declaración de las Naciones Unidas sobre los Derechos de los Pueblos Indígenas (2007) que desarrolla la obligación estatal correspectiva de obtener el consentimiento previo, libre e informado.

Si bien se trata de un instituto asociado a los derechos de los pueblos indígenas, proponemos además su aplicación extensiva a todas las comunidades locales cuando se trate de emprendimientos o actividades que involucren un impacto cultural o ambiental en sentido amplio (comprensivo no solo del ambiente natural sino también el cultural), o la realización de megaproyectos que puedan afectar la sustentabilidad del modo de vida de una comunidad.

El consentimiento previo, libre e informado supone un plus frente a la audiencia pública, en tanto no sólo tiene en cuenta la opinión sino que involucra la co-decisión de los afectados.

Nos interesa destacar también que desde la concepción de derechos humanos que hemos sostenido en esta tesis no se reduce a enunciados normativos ni sus garantías a las jurídicas, por lo que insistimos en que el desarrollo de garantías políticas y sociales como las aquí propuestas potenciará su consolidación.

\section{b) Involucrar a los colectivos subalternizados en la política patrimonial, y fortalecer las memorias alternativas a las oficiales, para garantizar el acceso y goce democráticos de los patrimonios}

El segundo reto requiere identificar los colectivos que no se encuentran representados o que están sub-representados en el discurso patrimonial para adoptar medidas que los involucren. En este sentido, el necesario relevamiento de patrimonios culturales del estado argentino requiere de medidas específicas de acción positiva, que involucren y estimulen la participación de aquellos colectivos que se encuentran históricamente segregados del discurso patrimonial, en articulación con diferentes actores sociales implicados en la cuestión. 
A su vez, es necesario reconocer posibles interpretaciones divergentes en que ciertas personas o grupos se sientan representadas y otros no en relación con ciertos elementos específicos del patrimonio cultural, y que, en el devenir del tiempo, las ideas y los significados sobre qué es y para qué se conserva determinado elemento patrimonial pueden cambiar.

El reto consiste, como lo ha señalado la experta en materia de Derechos Culturales, "en encontrar la forma en que las propias comunidades de origen se vean capacitadas para participar activamente en todo el proceso de determinación, selección, clasificación, interpretación, conservación y salvaguardia, administración y desarrollo del patrimonio cultural" (A/HRC/17/38 § 80, c).

En este sentido, es necesario que los profesionales y las instituciones involucradas en la gestión patrimonial, como depositarias de patrimonio cultural, establezcan relaciones más sólidas con comunidades y grupos y respeten sus contribuciones en cuanto al modo en que son interpretadas y representadas sus identidades.

\section{c) Recuperar la dimensión territorial desde una concepción comunitaria de la propiedad, que se asiente sobre su función social}

El último desafío, y quizá el más difícil, propone repensar las relaciones entre propiedad y patrimonio para proponer modelos alternativos de gestión comunitaria.

La sostenibilidad y continuidad de la gestión patrimonial se hace dificultosa cuando es impuesta desde afuera de las comunidades, por expertos o funcionarios públicos. No son pocos los ejemplos que dan cuenta de la realización de obras de conservación de bienes culturales en nuestra provincia, que al poco tiempo se vieron abandonados y nuevamente desvalorizados.

Otras experiencias dan cuenta de que en los casos en que las comunidades organizadas han podido liderar el proceso de patrimonialización y conseguido formas de autogestión, en los que los expertos han jugado un rol de orientadores, los proyectos se han mantenido a largo plazo (NUÑEZ, 2013, p. 10).

Las cuestiones de derechos humanos que involucra la gestión de los patrimonios culturales requieren que, desde formas organizativas locales, se propicien reapropiaciones 
y resignificaciones de los patrimonios culturales, desde el desarrollo de metodologías de investigación participativa, selección, manejo e interpretación de bienes culturales que permitan revincular los patrimonios con las comunidades, para desarrollar proyectos colectivos a partir de sus propios referentes estéticos y modos de pensar (NUÑEZ, 2013, p. 11).

Ello exigirá, en algunos casos, la repatriación de piezas arqueológicas, museológicas y restos óseos. Esta es una cuestión que produce una gran preocupación frente a la comunidad científica, en cuanto al manejo de estos bienes.

Sin embargo, es necesario no perder de vista que son los usos, los contextos y los criterios de valoración de las comunidades los que dan vida a sus patrimonios culturales.

De esta manera,

la restitución de una pieza de museo es un acto simbólico y social, donde se cuestiona la autoridad del museo sobre la significación y uso de las piezas y se abre la posibilidad de reconocer la validez de otros sistemas simbólicos y lógicas de pensamiento (NUÑEZ, 2013, p. 16).

La opción por la propiedad y gestión comunitaria de ciertos bienes culturales no debe descartarse, e implica una forma concreta de involucramiento de la comunidad en la sostenibilidad y subsistencia de su patrimonio.

\section{CONCLUSIONES}

El derecho humano a los patrimonios culturales involucra no sólo la dimensión orientada hacia el pasado, sino su actualidad y su proyección intergeneracional. Requiere articular la construcción de la memoria siempre en proceso abierto, con la dimensión sincrónica del carácter popular y vivo de las manifestaciones que integran los patrimonios culturales.

Este derecho humano necesita, además de las garantías jurídicas de amplia legitimación activa judicial inherentes a su carácter de derecho colectivo, las garantías políticas de la participación social en el acceso a la información, la consulta, la decisión, la gestión, el seguimiento y el control de los patrimonios culturales, lo que marca una necesaria obligación en la forma de elaborar e implementar las políticas públicas en todos 
los niveles del estado, en cogestión con la sociedad civil. De este modo, es preciso redefinir normas y políticas que garanticen las dimensiones personales, individuales homogéneas y/o colectivas de los mismos.

Es que, desde su indivisibilidad e interdependencia, todas las categorías de derechos, incluso los 'personalísimos', remiten a esa dimensión relacional de los bienes públicos que les son inherentes, que modulan los contenidos, inciden en la forma histórica de comprenderlos, y de disputarlos. Al mismo tiempo y justamente por eso, los bienes relacionales que son condición de posibilidad e integran el contenido de los derechos, no se corresponden con una dimensión ni homogénea, ni puramente estatal, ni exclusivamente personal, sino social, y por lo tanto siempre en algún grado deliberativa y conflictiva. Eso es lo que permite que las formas de comprender y practicar los derechos humanos tengan una dimensión siempre abierta y dinámica que excede la normatividad instituida.

En el caso del derecho humano a los patrimonios culturales esta tensión se hace evidente al remitir a locis y topois que son objeto de construcción social y polémica -pensemos en los temas o personajes históricos a monumentalizar o desmonumentalizar, los lugares de memoria, la construcción social de la verdad, la tensión entre selectividad social de las actividades de declaración, clasificación, listado y catalogación con la multiformidad del pluralismo social de una cultura con historia, pero viviente y dinámica)El lugar que en esos procesos toman lo tremendum horrendum y lo tremendum fascinosum en la construcción de memoria y procesos de identificaciones históricas, las tensiones permanentes entre simbólicas simétricas -mercado, contrato, ágora- y asimétricas -desde las alteridades invisibilizadas, excluidas, humilladas y su disenso- que están presentes en la comprensión cultural de todos los derechos humanos, son, en el caso del derecho humano a los patrimonios culturales, insumos más importantes aún.

De ahí la importancia y urgencia de desarrollar los derechos culturales desde prácticas e investigaciones que permitan sus garantías, concreción normativa, la proyección y evaluación críticas de las políticas públicas, desde el protagonismo de la participación de las sociedades civiles concernidas. 
Un ejemplo dramático de la actualidad del género de problemas a los que remite y trata el texto que el público tiene entre manos, es el de la Ciudad Sagrada de los Quilmes, en Tucumán (Argentina), cuya significación disputada entre territorio ancestral, lugar de identificación simbólico ritual vital para la existencia y reproducción cultural de la comunidad o su clasificación como 'ruinas' de interés turístico a poner en valor económico como patrimonio del estado provincial, es un botón de muestra. No se trata de un problema meramente teórico ni conceptual, sino de un caso que muestra la pervivencia cambiante de la matriz de colonialidad del poder y del ejercicio de violencia no meramente simbólica frente a los pueblos originarios. La consideración de los patrimonios culturales como derechos humanos exige la definición de quiénes son sus sujetos titulares y cuáles son las garantías jurídicas, políticas y las responsabilidades públicas para su efectivización. En el conflicto de valoraciones, se privilegia el interés económico privado y estatal, se criminaliza la protesta social legítima que reclama por los derechos históricamente negados de los pueblos. Por eso hemos puesto más arriba que el derecho a los patrimonios culturales es "nuevo" para el mainstream de los derechos humanos, pero es el fundamental y básico derecho colectivo para los pueblos originarios que se juegan, en casos como éste, su persistencia en el ser.

En definitiva, la protección de los patrimonios culturales involucra cuestiones de derechos humanos que deben ser consideradas a la hora de establecer mecanismos jurídicos, sociales y políticos de garantía, de modo de asegurar la participación de personas, grupos y comunidades en las políticas de selección y gestión patrimonial. Este trabajo, es un aporte a la definición del contenido de este derecho humano, en pleno desarrollo.

\section{REFERENCIAS}

AGAMBEN, G. ¿Qué es un dispositivo? Sociológica, ano 26, 73, p. 249-264, mai./ago. 2011. BADENES, D. Restos humanos en el Museo de Ciencias Naturales de la UNLP. Trofeos de guerra. Revista La Pulseada, n. 43, 2006.

BALLART, J. El patrimonio histórico y arqueológico: valor y uso. Barcelona: Ariel, 1997. 
BEGUELIN, M.; GOMEZ, S. Restitución de restos humanos: debates actuales y posibles escenarios futuros. In: Actas del X Congreso Argentino de Antropología Social. Buenos Aires: U.B.A, 2011.

BRIONES, C. Formaciones de alteridad: contextos globales, procesos nacionales y provinciales. In: Claudia Briones (comp.). Cartografías Argentinas. Políticas indigenistas y formaciones provinciales de alteridad. Buenos Aires: Antropofagia, 2005. p. 9-36.

CANÇADO TRINDADE, A. A. Derechos de solidaridad. In: A. A. Cançado Trindade (coord..) Estudios Básicos de Derechos Humanos, Tomo I. San José, Costa Rica: Instituto Interamericano de Derechos Humanos, 1994. p. 63-73.

COLOMBATO, L. El derecho al(os) patrimonio(s) cultural(es). Aportes a la definición de su contenido. Revista del Equipo Federal de Trabajo, n. 102. Disponível em: http://newsmatic.com.ar/conectar/245/102/articulo/3524/El-derecho-al-patrimonioculturalAportes-a-la-definicion-de-su-contenido.html. Acesso em: 8 jun. 2015.

COLOMBATO, L. Avances, frenos y retos en la consolidación del patrimonio cultural como derecho humano. In: Actas deIVII Congreso del IRI (I Congreso del CoFEI / II Congreso de la FLAEI). La Plata, 2014. Disponível em: http://congresos.unlp.edu.ar/index.php/CRRII/CRRIIVII/paper/view/1640. Acesso em: 8 jun. 2015.

DUSSEL, E. Derechos vigentes, nuevos derecho y derechos humanos. Revista Crítica Jurídica, 29, p. 229-235, jan./jun. 2010.

ENDERE, M. L.; ROLANDI, D. Legislación y Gestión del Patrimonio Arqueológico. Breve reseña de lo acontecido en los últimos 70 años. Relaciones de la Sociedad Argentina de Antropología XXXII, p. 33-54, 2007.

GALI BOADELLA, M. La gestión y conservación del patrimonio urbano desde la perspectiva de la historia del arte. In: M. Viladevall i Guasch (Coord.). Ciudad, Patrimonio y Gestión. Puebla: Benemérita Universidad Autónoma de Puebla, Dirección General de Fomento Editorial. Gobierno del Estado de Puebla, Secretaría de Cultura, p. 33-49, 2001.

GALLARDO, H. Teoría crítica: Matriz y posibilidad de los derechos humanos. México D.F.; Comisión Estatal de Derechos Humanos; Universidad Autónoma de San Luís Potosí, 2008.

GARGALLO, F. ¿Hacia un feminismo no occidental?. In: Francisca Gargallo. Ideas Feministas Latinoamericanas. Fundación Editorial el Perro y la Rana, p. 197-219, 2006.

GONZALEZ, Joaquín V. El juicio del siglo. Buenos Aires: Centro Editor de América Latina, 1979.

GRIMSON, A. Nuevas xenofobias, nuevas políticas étnicas en Argentina. In: Alejandro Grimson; Elisabeth Jelin (comps.). Migraciones regionales hacia la Argentina. Diferencias, desigualdades y derechos. Buenos Aires: Prometeo, 2006. p. 66-97.

HERNANDEZ i MARTI, G. M. Un zombi de la modernidad: el patrimonio cultural y sus límites. La Torre del Virrey: revista de estudios culturales, 5, p. 27-38, 2008. 
HERRERA FLORES, J. Los derechos humanos como productos culturales. Crítica del humanismo abstracto. Madrid: Los libros de la catarata, 2005.

LEHMAN-NISCHE, R. Catálogo de la Sección de Antropología del Museo de La Plata. Buenos Aires: Coni Hnos, 1910.

LLULL PEÑALBA, J. Evolución del concepto y de la significación social del patrimonio cultural. Arte, Individuo y Sociedad, 17, p. 175-204, 2005.

$\mathrm{MEDICl}, \mathrm{A}$. El malestar en la cultura jurídica. Ensayos críticos sobre políticas del derecho y derechos humanos. La Plata: Edulp - Editorial de la Universidad Nacional de La Plata, 2011.

$\mathrm{MEDICl}, \mathrm{A}$. Nuevo constitucionalismo latinoamericano y giro decolonial Seis proposiciones para comprenderlo desde un pensamiento situado y crítico. El Otro Derecho, 48, p. 19-62, 2013.

MORONI, M. La incorporación de los Territorios Nacionales en el proceso de consolidación del Estado Argentino. El caso del Territorio de la Pampa Central. Revista Andes, 16, 2005. Antropología e Historia. CEPIHA. Facultad de Humanidades. Universidad Nacional de Salta, 2015.

MIGNOLO, W. Introducción. In: Walter Mignolo (comp.) Capitalismo y Geopolítica del Conocimiento: el Eurocentrismo y la Filosofía de la Liberación en el Debate Intelectual Contemporáneo. Madrid: Ediciones del Signo, 2001, p. 9-53.

NUÑEZ, A. Resignificaciones y reapropiaciones del patrimonio cultural. Baukara 4 Bitácoras de antropología e historia de la antropología en América Latina, Bogotá, p. 6-21, nov. 2013.

QUIJANO, A. Colonialidad del poder y clasificación social. En Santiago Castro Gómez y Ramón Grosfoguel (comp.). El giro decolonial: reflexiones para una diversidad epistémica más allá del capitalismo global. Bogotá: Siglo del Hombre Editores; Universidad Central, Instituto de Estudios Sociales Contemporáneos y Pontificia Universidad Javeriana, Instituto Pensar, 2007. p. 93-126.

SOUSA SANTOS, B. Direitos Humanos: o desafío da interculturalidade. Revista Direitos Humanos, 2, p. 10-18, jun. 2009.

SEGATO, R. L. Los cauces profundos de la raza latinoamericana: una relectura del mestizaje. Crítica y Emancipación, 3, p. 11-44, 2010.

SYMONIDES, J. Derechos culturales: una categoría descuidada de derechos humanos. Revista Internacional de Ciencias Sociales, n. 158, UNESCO. Disponível em: http://red.pucp.edu.pe/ridei/wp-content/uploads/biblioteca/090914.pdf. Acesso em: 11 jun. 2011.

SZURMUK, M.; Mc KEE, R. Diccionario de estudios culturales latinoamericanos. México: Instituto Mora-Siglo XXI Editores, 2009.

TELLO, A. M. La (in)disposición ficcional del patrimonio cultural: Relatos subalternos de la ciudad de Lota. In: Actas del III Congreso Interoceánico de Estudios Latinoamericanos, Mendoza, publicación en CD Rom, 2007. 
TELLO, A. M. Notas sobre las políticas del patrimonio cultural. Cuadernos Interculturales, 8,15, p. 115-131, 2010.

VILADEVALL i GUASCH, M. Introducción. In: M. Viladevall I Guasch (Coord.). Gestión del patrimonio cultural: Realidades y retos. Puebla: Benemérita Universidad Autónoma de Puebla - Dirección General de Fomento Editorial, 2003. p. 17-22.

COLOMBATO, Lucía Carolina; MEDICI, Alejandro Marcelo. El derecho humano a los patrimonios culturales en clave decolonial. RBSD - Revista Brasileira de Sociologia do Direito, v. 3., n. 3, p. 67-95, set./dez. 2016. 